\begin{tabular}{lllllll}
\hline \multirow{2}{*}{\multicolumn{1}{c}{ Session }} & \multicolumn{5}{c}{ Replies very much } \\
\cline { 2 - 8 } & $\begin{array}{l}\text { Relevant } \\
\text { content }\end{array}$ & $\begin{array}{l}\text { Useful to } \\
\text { practice }\end{array}$ & $\begin{array}{l}\text { Well } \\
\text { delivered }\end{array}$ \\
\cline { 2 - 8 } & $\%$ & Rank & $\%$ & Rank & $\%$ & Rank \\
\hline Opportunities and possibilities & $85 \%$ & 1 & $75 \%$ & 2 & $65 \%$ & 5 \\
Where is CSI and Hospice UK & $60 \%$ & $7=$ & $71 \%$ & $5=$ & $59 \%$ & 8 \\
Organisational readiness & $78 \%$ & 2 & $71 \%$ & $5=$ & $76 \%$ & $2=$ \\
Change management & $74 \%$ & 4 & $74 \%$ & $3=$ & $86 \%$ & 1 \\
Feedback (individual, team, business & $68 \%$ & 6 & $74 \%$ & $3=$ & $70 \%$ & 4 \\
intelligence) to improve care & & & & & & \\
Dissemination and communicating & $60 \%$ & $7=$ & $66 \%$ & 8 & $60 \%$ & 7 \\
Accreditation & $36 \%$ & 9 & $30 \%$ & 9 & $41 \%$ & 9 \\
Tips for teaching & $76 \%$ & 3 & $78 \%$ & 1 & $76 \%$ & $2=$ \\
Front line reflections & $69 \%$ & 5 & $70 \%$ & 7 & $62 \%$ & 6 \\
\hline
\end{tabular}

Thematic analysis of the comments identified the value of networking with others to discuss, reflect experiences, leadership and implementation issues.

Conclusion The evaluation shows the importance of designing workshops to include clinical competences (e.g. knowing and teaching OACC measures) and aspects such as quality (e.g. feedback to improve care), leadership (e.g. change management/ organizational readiness) and developing self (e.g. reflection and networking). This is compatible with end of life competency frameworks such as Taylor (2016).

Furthermore, the comments indicate the importance of networks of learning to include communities of practice (e.g. space to test ideas), social networks (e.g. opinion and experiences) and teams to share knowledge (e.g. resources) (Jarche 2016). The evaluations emphasised the value of designing workshops to combine clinical expertise with leadership, quality and ongoing networks of learning and resources considerations. This is helpful in the design of future resources and programmes.

\section{P-58 'HOW ARE YOU?' - AN OUTCOMES BASED TOOL TO MEASURE THE IMPACT OF A HOSPICE COUNSELLING AND SUPPORT SERVICE FOR CHILDREN AND YOUNG PEOPLE}

Sharon Quinn. St Luke's Hospice, Basildon, UK

\subsection{6/bmjspcare-2016-001245.82}

The need to measure effectiveness of counselling interventions offered to children and young people is becoming ever more crucial in helping to sustain funding for services, gather evidence for service development and articulate the impact on the individual child/young person. The newly established 'How Are You?' tool has been used with children and young people (aged five years 19 years) at counselling or family support sessions (at 1, 4 and 7 or 8) to try and capture their self- reported progress. The tool contains a combination of 'smiley faces' ratings scales and ladder (likert) scales. Each section aims to gain a sense from the child about issues such as:

- Feelings

- Their sense of isolation

- Concentration levels

- Resilience levels.
The tool has proved to be user friendly with the children/ young people and has yielded interesting and illuminating results which clearly highlight their progress throughout the contact with the service. Benefits of its use have included:

- Offering an affirming map of progress for the individual when children and young people see where they were and where they are now at the end of the sessions

- Identifying clear impact of investment to report back to funders

- Validates the role of the counsellors/family support workers

- Allows comparison of data between children/young people who have required pre-bereavement support or experienced bereavement through different causes.

Results are portrayed in terms of percentage of those who have made progress during their contact with the service and can be used in conjunction with more qualitative data, observations and case studies to comprehensively evaluate the sessions and overall service.

\section{P-59 IN PARTNERSHIP WITH PEOPLE WITH PERSONAL EXPERIENCE: HOW DO USERS FIND 'VIEWS ON CARE' (PART OF THE OACC SUITE OF MEASURES)}

Charlotte Harrison, David Barclay. St Wilfrid's Hospice, Eastbourne, UK

\subsection{6/bmjspcare-2016-001245.83}

Background Views on Care is one measure of the Outcome Assessment and Complexity Collaboration (OACC) suite of measures. Views on Care focuses specifically on the patient's quality of life and their views on the impact of the service on their main problems and wellbeing. Outcome measures in specialist palliative care are important in evaluating the quality of care provided. As part of the introduction of all OACC measures, Views on Care was piloted on our 15 -bed inpatient unit. To date, as Views on Care is a new measure, there are no data yet on the validity and reliability.

Aim To review how Views on Care is presented to our patients to ease completion

Methods In the introductory pilot of Views on Care two members of the medical team (authors) identified all patients receiving care during February 2016 who were assessed as being able to self-complete the Views on Care questionnaire. Feedback was gathered at the time and when collated both authors noted some patients had difficulty with the format. Because of the pilot experience we plan to bring the questionnaire to a focus group of people with personal experience to more formally review the use of the tool and, if necessary, look at ways to improve on our use of this measure. Results to date: 18 questionnaires completed $72 \%$ of patients reported feeling a little better or much better $89 \%$ of patients reported the Hospice was giving a lot of benefit. Example of Patient Comments: 'I cannot recall life before the Hospice'; 'I don't know which box to tick'.

Why is this important?

1. Majority of palliative care services are using or in the process of introducing OACC measures

2. Less is understood about the practicalities of the Views on Care tool. 